\title{
Determination of Cooling Rates by the Structure of Spinodal Decomposition and Impact Melting in Meteorite Substance
}

\author{
Razilia Muftakhetdinova*, Evgenia Brusnitsina, Grigoriy Yakovlev and Victor Grokhovsky \\ Extra Terra Consortium, Ural Federal University, Ekaterinburg, Russian Federation
}

Received: 01 August 2018; accepted: 18 December 2018

\begin{abstract}
Cooling rates of meteoritic iron-nickel alloys were estimated using a processing of morphological features of their structure. All data have been acquired with optical and scanning electron microscopy. Two types of cooling rates were obtained. Slow cooling during the formation of the meteoroid parent body determined the first type. The second type is a result of melt crystallization after a shock event.
\end{abstract}

Keywords: structure, meteorites, cooling rate, $\mathrm{Fe}-\mathrm{Ni}$ alloys, dendrite

\section{Introduction}

The development of modern industry can not be imagined without iron alloys. Earth's native iron is found mainly in the form of $\mathrm{Fe}-\mathrm{Ni}$ inclusions in metamorphic and sedimentary rocks. Also, $\mathrm{Fe}-\mathrm{Ni}-\mathrm{Co}$ alloys could be found in stone, iron, and stony-iron meteorites. Features of meteoritical structure formation were determined by the influence of space vacuum, extremely high and low temperatures, slow cooling (about tens of Kelvins per million years and lower), high pressures (up to $300 \mathrm{GPa}$ ), high-speed deformations (up to $10^{7}$ inverse seconds), and other effects. Such complex impact and thermal history resulted in different metal alloys microstructure of meteorites. One can find in meteoritic metal such phases as kamacite $\alpha-\mathrm{Fe}(\mathrm{Ni}, \mathrm{Co})$ with $\mathrm{Ni}$ content from $4 \%$ to $7.5 \%$, taenite $\gamma$ - $\mathrm{Fe}(\mathrm{Ni}, \mathrm{Co})$ with $\mathrm{Ni}$ content from $7.5 \%$ to $50 \%$, tetrataenite $\gamma^{\prime}-\mathrm{FeNi}$ intermetallic compound with an $\mathrm{L}_{0}$ structure, martensite $\alpha_{2}$, and plessite $(\alpha+\gamma)$ with various morphologies.

Often, new analytical capabilities are tested using meteoritic metal. Researchers began to use many new techniques over the last quarter of a century: FIB, computer tomography, nanoindenting, electron backscatter diffraction (EBSD), and image analysis. The EBSD method provides wide possibilities in acquiring local crystallographic information.

The conjunction of structures formed in states with high and low cooling rates in one sample is of interest. Chelyabinsk meteorite has the unique structure which meets this condition. Grokhovsky et al. [1] noted that there are low-shocked light and shock-melted dark areas in this meteorite. Latter contains gray subarea with remelted silicates and black subarea with remelted troilite. Estimation of meteoritical cooling rates in these zones is a useful method for better understanding of processes, which take place both during differentiation of various parent bodies and during a lifetime of a certain fragment of extraterrestrial matter. Based on the literature data, we found out that such a parameter as the cooling rate in a substance of extraterrestrial origin could be determined by the residual variation of microstructure.

Earlier, several techniques were suggested for measurement of meteoritical cooling rates. Goldstein et al. [2] estimated this parameter using the diffusion coefficients for $\mathrm{Ni}$ in $\mathrm{Fe}$. Another method [2, 3] was based on a processing of Ni concentration data across kamacite band and taenite-kamacite border. Later, the development of electron microscopy allowed

*Author for correspondence: gizrozka91@bk.ru. finding new zone which lies along these phases. Nanoscale round-shape tetrataenite $\gamma^{\prime}(\mathrm{FeNi})$ particles embedded in kamacite matrix have been termed "cloudy zone" or "cloudy taenite". An empirical relationship between the sizes of "clouds" and the cooling rate below $500{ }^{\circ} \mathrm{C}$ have been found $[4,5]$. Inverse relationship between cooling rate and particles size has been observed.

Fast crystallization of metallic melts often leads to dendrite formation. Experimental works in 70-s with $\mathrm{Fe}-\mathrm{Ni}$ alloys $[6,7,8]$ demonstrated that the distance between the dendrite secondary arms decreased with increasing cooling rate. Such crystals have also been found in Chelyabinsk meteorite [9]. Taenite dendrites in troilite matrix are situated in gas vugs formed due to shrinkage phenomena connected with crystallization of shock melt.

The aim of this work is to compare the cooling rates of various extraterrestrial matters, which is formed at different temperatures and time intervals and also to make assumptions about the thermal history of parent body formation.

\section{Experimental Details}

Samples with different shock histories and, consequently, various metal structures were studied in this work. In addition to meteorites and lunar particles, specially prepared meteoritic samples after shock-wave converging loading have been analyzed. Meteorites, namely, Seymchan (pallasite, PMG), Canyon Diablo (Iron, IAB-MG), Odessa (Iron, IAB-MG), and Chelyabinsk (LL5), have a slow cooling structure such as cloudy zone. Lunar metal particle 20045-544 was intended for correlation with the "natural" shocked Chelyabinsk sample, and samples of Chelyabinsk and Sikhote-Alin (Iron, IIAB) after the procedure of "terrestrial" loading have been investigated.

Samples were ground and polished using a standard technique. Polished sections were etched by Nital (2-4 vol \% $\mathrm{HNO}_{3}$ solution in ethanol). Microstructure studies were accomplished using a Zeiss Axiovert 40 MAT optical microscope and a scanning electron microscope Carl Zeiss Ligma VP. Measurements of periodic structures have been done using a SIAMS 700 image analysis system.

Slow cooling of extraterrestrial iron alloy $\left(10-100{ }^{\circ} \mathrm{C} / \mathrm{Myr}\right)$ resulted in formation of nickel gradient as well as various structural component. In particular, the cloud zone consists of particles of the ordered phase FeNi with structural type $\mathrm{L}_{0}$ in the matrix of the $\alpha$-phase [10]. One of the first descriptions of this structure was published in the journal Nature in 1979 


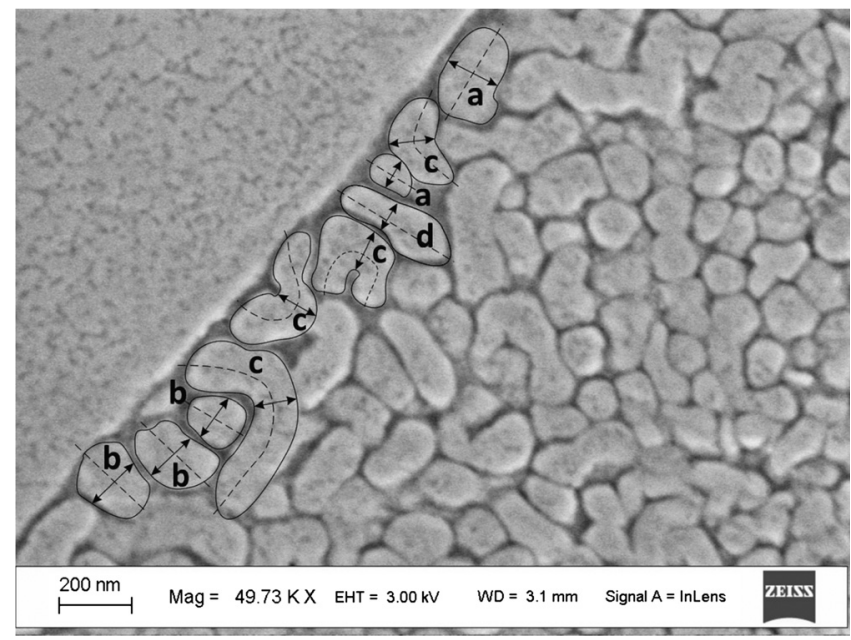

Figure 1. Measurements of sizes of cloudy zone particles in Seymchan meteorite

[11]. Small sizes of tetrataenite particles was a reason for using a scanning electron microscope. Acquired images have been processed according to the scheme suggested in ref. 4 . Application of this technique is shown in Figure 1. Size of the particle was measured across the diameter for the near-spherical "clouds". For the potato-shaped particles (a), the size of the particle is the width along the minor axis. For the egg, banana, and raindrop shapes (b-d), the width is measured along the minor axis which splits the major axis of the particle in two.

Both optical and scanning microscopy techniques were used for cooling rate estimation in the case of shocked samples. All of them demonstrated various structures of dendrite crystals.
It was shown in experimental studies [6-8] that the distance between the secondary arms of dendritic crystals $d(\mu \mathrm{m})$ in alloys $\mathrm{Fe}-10 \% \mathrm{Ni}$ is inversely proportional to the cooling rate $(V)$ in the crystallization range. The following relationship between $V\left({ }^{\circ} \mathrm{C} / \mathrm{s}\right)$ and this distance was proposed in ref. 12:

$$
V=5.3 \times 10^{5} d^{-2.9}
$$

There is another relationship in a wide range of cooling rates for $\mathrm{Fe}-\mathrm{Ni}$ and $\mathrm{Fe}-\mathrm{P}$ alloys [6].

$$
V=3.6 \times 10^{5} d^{-3.125}
$$

where $d(\mu \mathrm{m})$ is the distance between the secondary dendrite arms or the cell size, and $V\left({ }^{\circ} \mathrm{C} / \mathrm{s}\right)$ is the cooling rate in the crystallization range.

We used both formulas to estimate the cooling rate and then compare them.

\section{Results and Discussion}

As well as any other chondrite, Chelyabinsk meteorite contains small metal grains. The thorough search in white lithology after etching resulted in finding of cloudy zone with an average size of high nickel particles equal to $146 \mathrm{~nm}$ (Figure 2). Cooling rates of 3 iron meteorites (iron part of Seymchan, Canyon Diablo, and Odessa) have also been measured using the same technique from [4]. The average size of high nickel particles in Seymchan is equal to $122 \mathrm{~nm}$, for Chelyabinsk, Canyon Diablo and Odessa this value is equal to $146 \mathrm{~nm}, 88$ $\mathrm{nm}$ and $110 \mathrm{~nm}$ respectively (Figure $2 \mathrm{a}-\mathrm{d}$ ).

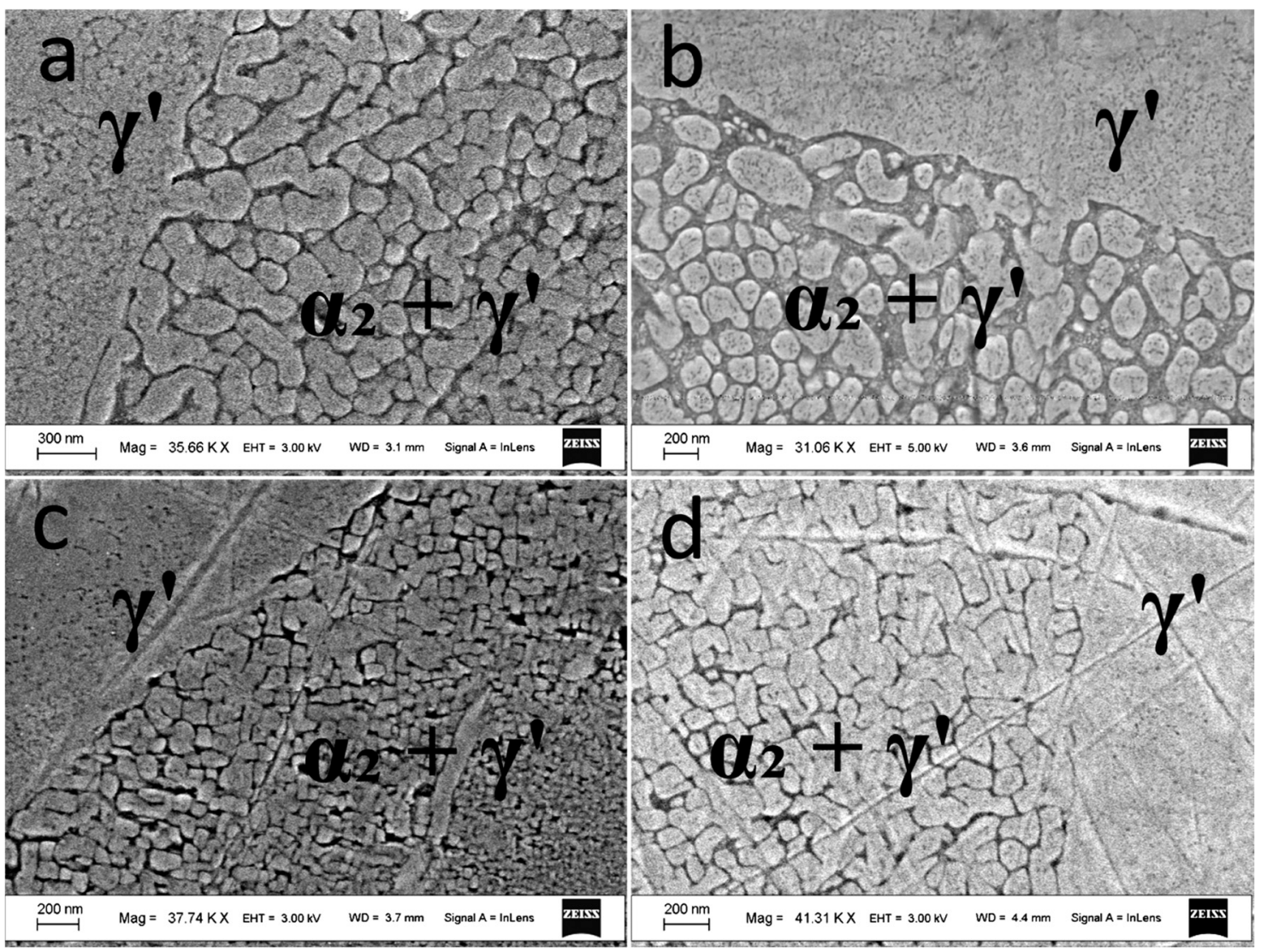

Figure 2. SEM images of the cloudy zone microstructure of metal in meteorites: a) Seymchan, b) Chelyabinsk, c) Canyon Diablo, and d) Odessa meteorite 


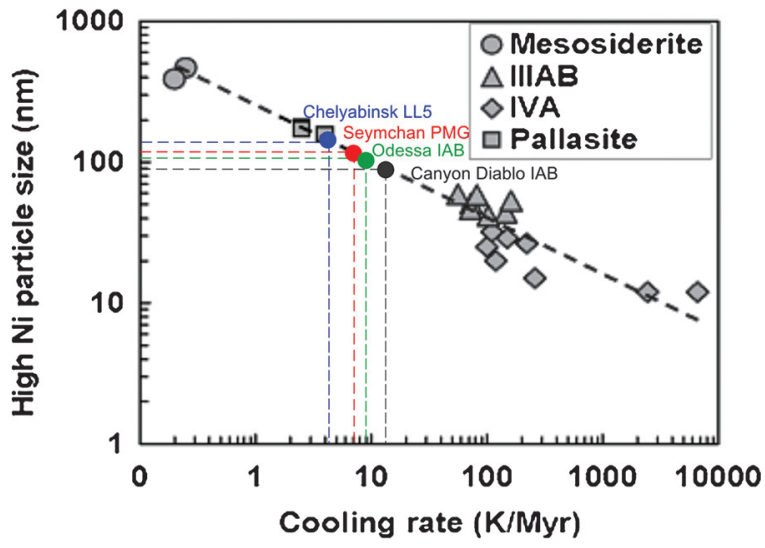

Figure 3. Variation of high-Ni particle size versus metallographic cooling rate in mesosiderites, pallasites, IIIAB, and IVA irons [Goldstein, 2009] with our results
We add our data to the "size of particles vs. cooling rate" plot for temperature below $500{ }^{\circ} \mathrm{C}(723 \mathrm{~K})$ (Figure 3) $[4,13]$. According to this relationship, cooling rates for Seymchan, Canyon Diablo, and Odessa are $7 \mathrm{~K} / \mathrm{Myr}, 15 \mathrm{~K} / \mathrm{Myr}$, and $9 \mathrm{~K} / \mathrm{Myr}$, respectively. The cooling rate of metal grains in Chelyabinsk meteorite was estimated as $4 \mathrm{~K} / \mathrm{Myr}$.

With regard to gray lithology, these fragments of Chelyabinsk meteorite do not show cloudy zone and other signs of slow cooling. An absence of typical structures for an ordinary chondrites and existence of dendrites are evidence of remelting and fast cooling, probably due to impact event (Figure 4). Cooling rates in this case could be estimated using dendrite arm spacing. The mean distance between dendrite secondary arms is $25 \mu \mathrm{m}$ for a "natural" impact sample and $20 \mu \mathrm{m}$ for a sample compressed by converging shock waves, respectively. One can substitute this value into Eqs. (1) and (2).

Thus, the cooling rate is $42{ }^{\circ} \mathrm{C} / \mathrm{s}$ and $14{ }^{\circ} \mathrm{C} / \mathrm{s}$ by Eqs. (1) and (2), respectively. The calculated rates are within one order

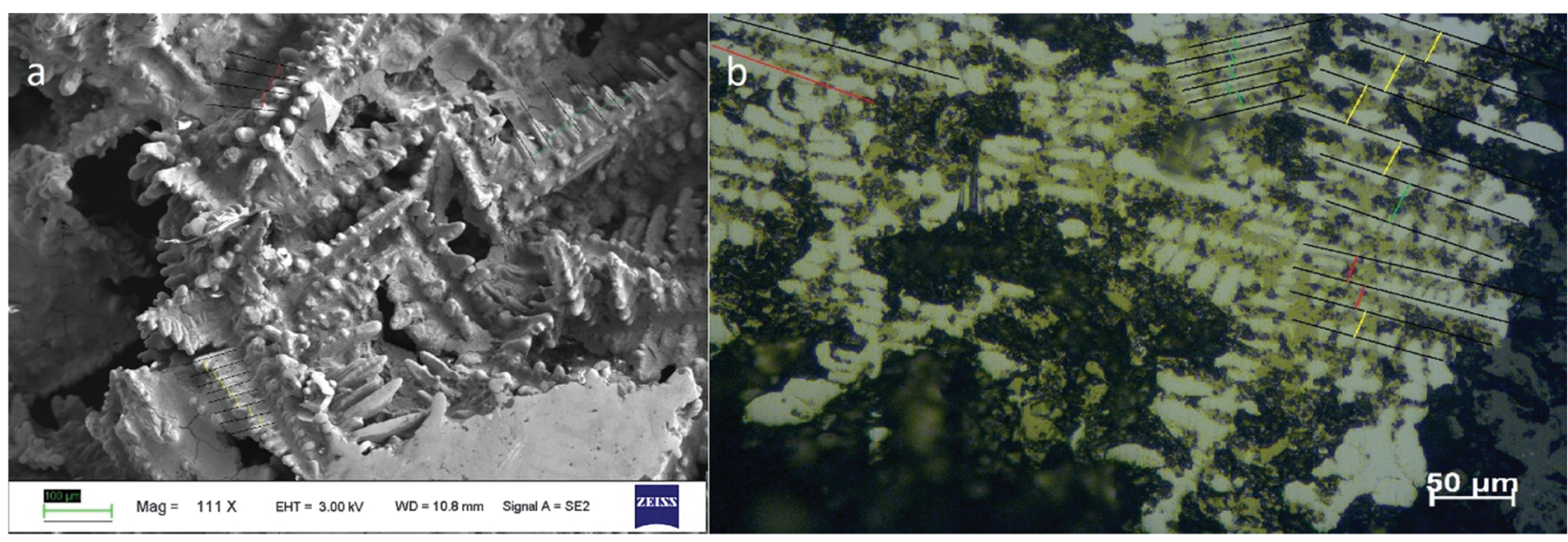

Figure 4. Dendritic structure: a) SEM image in vugs, gray lithology of Chelyabinsk meteorite and b) OM image in impact melting of Chelyabinsk LL5 ordinary chondrite after shock loading

Table 1. Calculations of the cooling rate for various meteorites

\begin{tabular}{lccc}
\hline Sample Name & $\begin{array}{c}\text { The distance between the } \\
\text { secondary dendritic axes or } \\
\text { the width of the cells }(\mu \mathrm{m})\end{array}$ & $\begin{array}{c}\text { Cooling rate according } \\
\text { to the formula: } \\
V=5.3 \times 10^{5} d^{-2.9}{ }^{\circ} \mathrm{C} / \mathrm{s}\end{array}$ & $\begin{array}{c}\text { Cooling rate according } \\
\text { to the formula: } \\
V=3.6 \times 10^{5} d^{-3.125}{ }^{\circ} \mathrm{C} / \mathrm{s}\end{array}$ \\
\hline Sikhote-Alin (after shock loading) & 2 & 71,000 & 33,000 \\
Chelyabinsk LL5 (Impact melt zone) & 26 & 42 & 14 \\
Chelyabinsk LL5 (after shock loading) & 20 & 85 & 30 \\
Metallic particle 20,045-544 of the lunar soil & 60 & 3,69 & 1 \\
\hline
\end{tabular}

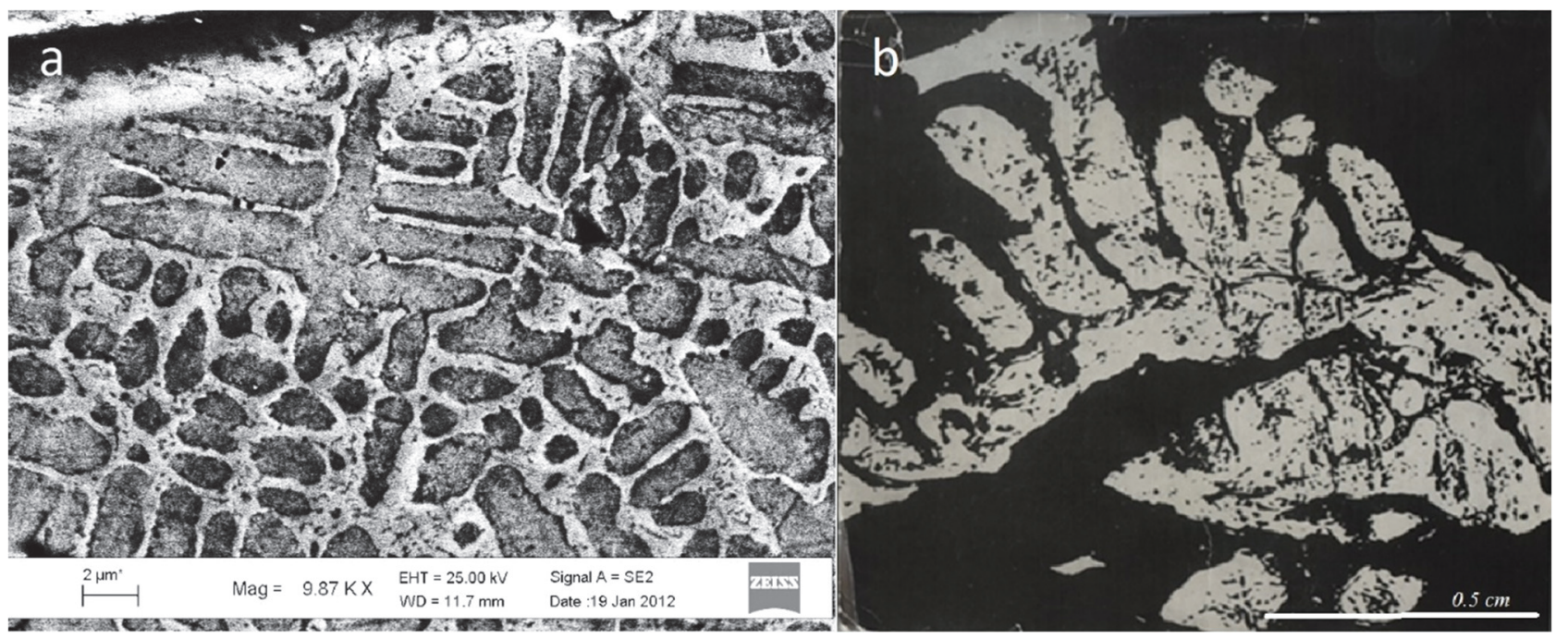

Figure 5. a) SEM image of the melting and crystallization region in the Sikhote-Alin meteorite after loading by converging shock waves; b) Optical image of a dendritic structure in a metallic particle 20045-544 of the lunar soil 
of magnitude. Such a rapid cooling rate of the meteorite Chelyabinsk can be explained by events associated with the interaction of the meteorite parent body with a cooler body and the transfer of heat. Some authors associate high cooling rates with the transfer of heat by radiation or due to thermal conductivity through silicate materials. The obtained results of cooling rates are consistent with the previously known data for other meteorites. The results of calculations and parameters of the dendritic structure of other samples are given in Table 1 .

For the Sikhote-Alin iron meteorite sample (Figure 5a), we obtained very large values of the cooling rates, by extrapolating the linear dependence to the region of small interdendritic distances. Such velocities can be related to the physical parameters (temperature, pressure, and high-speed deformation) of converging shock waves experiments.

Cross-cut of 20045-544 (Figure 5b) has a treelike shape. Silicate matter has been found in dendrite base. Existing liquation gradients of $\mathrm{Fe}, \mathrm{Ni}$, and $\mathrm{Co}$ are directed toward the growth of dendritic branches [6]. Curvature of dendritic primary arms has been found. This deformation resulted in $5-12^{\circ}$ shift of adjacent grains. The distance between second arms after virtual curvature compensation is about $60 \mu \mathrm{m}$. It was estimated that particle like 20045-544 was formed with a cooling rate of $1{ }^{\circ} \mathrm{C} / \mathrm{s}$. Research of lunar soil particles confirms the shock origin of matter transformation. Processes of shock melting and subsequent recrystallization with a cooling rate in the range of at least 0.1 to $1{ }^{\circ} \mathrm{C} / \mathrm{s}$ are possible on lunar surface. Physical and chemical laws of phase formation in $\mathrm{Fe}-\mathrm{Ni}-\mathrm{Co}-\mathrm{P}-\mathrm{S}$ system are valid under such conditions, but some phenomena like the absence of microporosity demonstrate process features.

\section{Conclusions}

Quantitative characteristics of metallographic structures in meteorites obtained by optical and electron microscopy techniques give us an opportunity to estimate the cooling rates and to suggest the thermal history of the meteoroid in different temperature ranges. The meteorites Seymchan, Canyon Diablo, and Odessa in the temperature range of spinodal decomposition (below $500{ }^{\circ} \mathrm{C}$ ) were cooled at rates of about 7-15 K/Myr. The presence of dendrites indicates the crystallization of the shock melt. The average size $(26 \mu \mathrm{m})$ of dendrites in the vugs of the impact melt of the Chelyabinsk meteorite indicates that the cooling rate in the temperature range of crystallization of the $\mathrm{Fe}-\mathrm{Ni}-\mathrm{Co}$ meteorite alloy is about less than 50 degrees per second, while the metal structure in the unshocked part of this meteorite indicates a cooling rate about $4 \mathrm{~K} / \mathrm{Myr}$ at meteoroid formation. Converging shock wave loading of the Sikhote-Alin meteorite made it possible to realize melting and crystallization with a superfast cooling rate (order of several thousand degrees per second) of the impact melt in a local area. The shock remelting of an iron meteorite on the lunar surface formed a particle in the form of a dendrite with a cooling rate of 1 degree per second. The observed differences in cooling rates in the same substance prove a very complex shock and thermal history of meteorites.

Acknowledgments. This study was funded by Russian Foundation for Basic Research according to the research project No.18-38-00598 and the Ministry of Education and Science of the Russian Federation (projects 5.4825.2017/6.7 and 5.3451.2017/4.6).

Open Access. This is an open-access article distributed under the terms of the Creative Commons AttributionNonCommercial 4.0 International License (https:// creativecommons.org/licenses/by-nc/4.0/), which permits unrestricted use, distribution, and reproduction in any medium for non-commercial purposes, provided the original author and source are credited, a link to the CC License is provided, and changes - if any - are indicated.

\section{References}

1. Grokhovsky, V. I.; Kohout, T.; Gritsevich, M.; Koneva, E. V. Meteoritics \& Planetary Science. 2014, 49, 5364.

2. Goldstein, J. I.; Hanneman, R. E. and Ogilvie, R. E. Trans. Met. Soc. A. I.M.E. 1964, 233, 812-820.

3. Wood, J. A. Icarus. 1964, 8, 429-459.

4. Goldstein, J. I.; Yang, J.; Kotula, P. G.; Michael, J. R. and Scott, E. R. D. Meteoritics \& Planetary Science. 2009, 44, 343-358.

5. Yang, C.-W.; Williams, D. B.; Goldstein, J. I. Meteoritics. 1997, 32, 423-429.

6. Flemings, M. C.; Poirier, D. R.; Barone, R. V.; Brody, H. D. J. of Iron Steel Inst. 1970, 208, 371-381.

7. Blau, P. J.; Axon, H. J.; Goldstein, J. I. J. Geophys. Research. 1973 78, 363-374.

8. Flemings, M. C. Solidification processing McGraw-Hill, New York, 1974, p. 416.

9. Sharygin, V. V.; Grokhovsky, V. I.; Yakovlev, G. A.; Sobolev, V. S. Meteorit. Planet. Sci. 2015, 5274.

10. Scott, E. R. D.; Krot, T. V.; Goldstein, J. I.; Wakita, S. Geochim. Cosmochim. Acta. 2014, 136, 13-37.

11. Jago, R. A. Nature. 1979, 279, 413-415,

12. Scott, E. R. D. Geochim. Cosmochim. Acta. 1982, 46, 813-823.

13. Goldstein, J. I.; Scott, E. R. D. and Chabot, N. L. Chemie der Erde. 2009, 69, 293-325. 